\title{
The barriers to adequate healthcare
}

An article in this issue deals with the difficulty, in a developing country, of accessing adequate health care. ${ }^{[1]}$ The article highlights infrastructural deficiencies within the society itself - a lack of private transport to take a patient, in this case with a maternity emergency, to a healthcare facility. This demonstrates that the resources within broader society and not merely within healthcare itself can affect how well or badly people are treated medically, though clearly the resources a government has allocated to the construction or maintenance of health facilities determines the distance to be travelled, and also determines the number of medical practitioners available at a facility and the resources available to them.

The same article deals with other factors, beyond the scope of government spending, that exist within a society that may limit a person's ability to achieve care, i.e. psychosocial factors within a culture. A woman, in a society that is overwhelmingly paternalistic, may, in order to make a journey to a facility, be dependent on the permission of a husband, or even male elders, who may lack insight into the need for care, and so travel and care may be delayed.

Societies in which there is significant recourse to traditional medicine or natural remedies may also experience delays in accessing conventional healthcare. That is not say that traditional medicine cannot possibly be effective, but in the case of a cord prolapse or severe growth restriction due to placental insufficiency recognised by the patient as diminished fetal movement, or in the case of an evolving abruption, traditional medicine may not be adequate, and may merely stall the process, preventing effective and sometimes life-saving treatment.

In order to establish effective healthcare, international, national and provincial institutions set objectives. The United Nations (UN) has Millennium Development Goals (MDGs) ${ }^{[2]}$ that relate directly or indirectly to health, now modified as the Sustainable Development Goals (SDGs). A deliberate stated attempt via the MDGs/SDGs to reduce maternal or infant mortality focuses attention and effort directly on health matters. The eradication of poverty may indirectly produce a benefit by improving personal access to transport, or may enable access to education creating an awareness of healthcare opportunities, and may create political consciousness that creates pressure from focus groups outside and inside governments to improve healthcare.

As the article in this issue suggests, the achievement of some MDGs instituted by the UN does not necessarily equate to a broad improvement in healthcare if they do not directly deal with the rate-limiting steps that inhibit adequate healthcare, or the factors that promote deficiencies of care. By analogy, those that harbour the immune deficiency virus HIV may be effectively treated with antiretroviral drugs and yet retain a predisposition to large vulvovaginal warts or vulvar intra-epithelial neoplasia, or even vulvar cancer. Rate-enhancing steps predisposing to these conditions remain unchallenged, and so the problems persist.

National and provincial governments may make any number of promises that relate to healthcare, without these necessarily being achieved. Appointment in health ministries may be determined by the ability of that person to reciprocate political favours rather than an ability to do the job, or an inclination to recognise and expose deficiencies of practice that would ultimately lead to improved effective care.

At the level of healthcare itself, effective medical care may be enhanced by medical protocols, evidence-based instructions for diagnosis and management that promote uniformity of treatment on tried and tested lines. Protocols may be regional or supra-regional, and may appear in booklets or posters in healthcare facilities. If $\mathrm{WiFi}$, cellphone coverage and cellphones or computers are available, international protocols and the latest debates and recommendations that inform the choice of interventions to maintain effective care can be accessed. However, those recommendations are of little value if there is no Amoxil in the cupboard, if there are no intravenous giving sets to replace fluid and no blood transfusion service to restore the urgently needed haemoglobin, nor Syntocinon or misoprostol to contract an atonic uterus, nor basic neonatal facilities to care for a baby in need of assistance.

Standards of effective healthcare may also be maintained by audit. The critical assessment of the care of patients may occur nationally, regionally or in a hospital or healthcare facility. Factors that affect deficient care may be patient-related or medical personnel-related, and may highlight a need for education, or may be infrastructurerelated and demonstrate the need for infrastructure improvement, or deficiencies may be resource-related, highlighting a need for the provision of the correct drugs or equipment or adequate numbers of staff. These resources are not always prohibitively expensive, but co-ordination and effective economical supply are required.

Deficiencies in healthcare are not solely confined to the developing world: inequalities in healthcare provision in the developed world are well known. The controversy over the medical insurance scheme known as 'Obamacare' - an intention by the ex-President of the USA to extend medical insurance to the less wealthy in a country significantly dependant on private healthcare - provides evidence for the difficulty of accessing adequate healthcare in the so-called First World. A Centre for Communicable Diseases report ${ }^{[3]}$ of 2007 claims that $20 \%$ of Americans, 45 million people, do not have access to basic medical care. This is in the world's poster child of development.

Healthcare provision in the developed world may also be limited from region to region by inequalities. The National Health Service (NHS), the state healthcare system in the UK, has been affected due to historical and current inequalities in wealth, general health and regional resource allocation, resulting in differences in anything from waiting times for elective procedures to differences in mortality. ${ }^{[4,5]} \mathrm{In}$ such a society, the awareness of what can be achieved in neighbouring health districts may result in the judgement of the local provision of care as inadequate.

A society can also be affected by a changing expectation over time. What is achieved in one decade may not be achieved in the next: again in the UK, dental care and an optician service were, up until the 1970 s, provided to all by the NHS. These services were subsequently withdrawn.

Regarding audit, any audit system designed to promote effective healthcare is only as effective as the policy change that follows. In the town of Bristol in the UK in the late 1980s and early 1990s, an audit of paediatric cardiac surgery demonstrated a two-fold increase 
in mortality of operated cases above accepted norms. The audit was ignored and disregarded in favour of protecting colleagues and existing processes. There were accusations of ulterior motives against the originator of the audit. This, after several years, was resolved by a public inquiry, ${ }^{[6]}$ which concluded that the medical profession had failed significantly to act. Audit without correction is wasted time and effort, and the deficiencies that are identified persist. This failed audit was instigated by a whistleblower. ${ }^{[7]} \mathrm{A}$ newspaper article published 10 years later in 2015 demonstrated that the treatment of whistleblowers in the UK NHS was so poor that government intervention was deemed necessary to ensure their protection. ${ }^{[8]}$ In many cases and in many parts of the world, it is the government itself that the whistleblower must fear.

The Bristol incident and others demonstrate that in any country vested interests and political pressure by those in power can prevent adequate, effective healthcare being achieved. This pattern of resistance to clear evidence for change has, unquestionably, been repeated throughout the world hundreds of thousands of times.

At a recent planning meeting to address deficiencies of healthcare, a training doctor turned and asked, 'Despite the fact that we have sat and addressed the achievable and unachievable issues in the healthcare that we provide, and we think we have tried hard enough, how will our efforts be judged in 10 years' time? Will we be judged favourably? Have we spoken the truth to power enough?' His implication was that we had not. How many of you are able to face those same questions confidently?
There are many factors that determine the adequacy or inadequacy of healthcare. A combination of all and a willingness to honestly face the issues and to tirelessly promote the measures required to tackle the deficiencies are the absolute prerequisites to making things better.

\section{William Edridge}

Editor

william.edridge@gmail.com

S Afr J Obs Gynae 2019;25(2):68. https://doi.org/10.7196/SAJOG.2020.v25i2.XXX

1. Wondu Y A, Dibaba B, Bayu M, Hussie M. Factors associated with maternal delays in utilising emergency obstetric care in Arsi Zone, Ethiopia. S Afr J Obstet Gynaecol 2019;25(2):56-63. https:// doi.org/10.7196/sajog.1437

2. The Millenium Development Goals(MDGs). Geneva: World Health organization, 2000. https:// www.who.int/topics/millennium_development_goals/about/en/(accessed 5 March 2020).

3. National Center for Health Statistics. Health, United States, 2007, with chartbook on trends in https://www.cdc.gov/nchs/data/hus/hus07.pdf (accessed 5 March 2020).

4. Barr B, Higgerson J, Whitehead M, Duncan WH. Investigating the impact of the English health inequalities strategy: Time trend analysis. BMJ 2017;358:j3310. https://doi.org/10.1136/bmj.j3310

5. Rimmer A. Waiting list situation is 'utterly unacceptable, say surgeons, who renew call for 5-year plan. BMJ 2019;366:15099. https://doi.org/10.1136/bmj.15099

6. Department of Health, UK. The report of the public inquiry into children's heart surgery at the Bristol Royal Infirmary 1984 - 1995: Learning from Bristol. London: Department of Health, 2002. https://webarchive.nationalarchives.gov.uk/20100407202128/http://www.dh.gov.uk/en/ Publicationsandstatistics/Publications/PublicationsPolicyAndGuidance/DH_4005620

7. BBC News. Bolsin: the Bristol whistleblower. news.bbc.co.uk, 2002. http://news.bbc.co.uk/2/hi/ health/532006.stm (accessed 5 March 2020).

8. Sawer P, Donnelly L. Meet the NHS Whistleblowers who exposed the truth. www.telegraph.co.uk, 11 February 2015. https://www.telegraph.co.uk/news/health/news/11398148/The-NHS-whistleblowers-who-spoke-out-for-patients.html (accessed 5 March 2020). 